\title{
Distinct transcriptomic responses of Caenorhabditis elegans to pristine and sulfidized silver nanoparticles
}

\author{
Daniel L. Starnes ${ }^{1}$, Stuart S. Lichtenberg ${ }^{1,2}$, Jason M. Unrine ${ }^{1,2}$, Catherine P. Starnes ${ }^{3}$, Emily K. Oostveen ${ }^{1}$, Gregory \\ V. Lowry ${ }^{2,4}$, Paul M. Bertsch ${ }^{1,2,5}$, and Olga V. Tsyusko ${ }^{1,2^{*}}$ \\ 1. Department of Plant and Soil Sciences, University of Kentucky, 1100 South Limestone Street, Lexington, Kentucky 40546, \\ United States \\ 2. Center for Environmental Implications of NanoTechnology (CEINT), P.O. Box 90287, Duke University, Durham, North \\ Carolina 27708-0287, United States \\ 3. Department of Statistics, University of Kentucky, 725 Rose Street, MDS Building 305, Lexington KY 40536, USA \\ 4. Department of Civil \& Environmental Engineering, Carnegie Mellon University, Pittsburgh, Pennsylvania 15213, United \\ States \\ 5. Division of Land and Water, CSIRO, Ecosciences Precinct, Brisbane, QLD Australia
}

TITLE RUNNING HEAD: Toxicogenomic responses to sulfidized Ag nanoparticles

*Corresponding Author email: olga.tsyusko@uky.edu, (859) 257-1777 


\title{
Capsule
}

The toxicity of fully sulfidized Ag nanoparticles is not due to release of Ag ions.

\begin{abstract}
Manufactured nanoparticles (MNP) rapidly undergo aging processes once released from products. Silver sulfide $\left(\mathrm{Ag}_{2} \mathrm{~S}\right)$ is the major transformation product formed during the wastewater treatment process for Ag-MNP. We examined toxicogenomic responses of pristine Ag-MNP, sulfidized Ag-MNP (sAg-MNP), and $\mathrm{AgNO}_{3}$ to a model soil organism, Caenorhabditis elegans. Transcriptomic profiling of nematodes which were exposed at the $\mathrm{EC}_{30}$ for reproduction for $\mathrm{AgNO}_{3}, \mathrm{Ag}-\mathrm{MNP}$, and sAg-MNP resulted in 571 differentially expressed genes. We independently verified expression of 4 genes (numr-1, rol-8, col-158, and grl-20) using qRTPCR. Only $11 \%$ of differentially expressed genes were common among the three treatments. Gene ontology enrichment analysis also revealed that Ag-MNP and sAg-MNP had distinct toxicity mechanisms and did not share any of the biological processes. The processes most affected by Ag-MNP relate to metabolism, while those processes most affected by sAg-MNP relate to molting and the cuticle, and the most impacted processes for $\mathrm{AgNO}_{3}$ exposed nematodes was stress related. Additionally, as observed from qRT-PCR and mutant experiments, the responses to $\mathrm{AAg}-\mathrm{MNP}$ were distinct from $\mathrm{AgNO}_{3}$ while some of the effects of pristine MNPs were similar to $\mathrm{AgNO}_{3}$, suggesting that effects from Ag-MNP is partially due to dissolved silver ions.
\end{abstract}

Keywords: antimicrobial, nanomaterial, toxicogenomics, soil, wastewater 


\section{Introduction}

Silver nanoparticles (Ag-MNP) are the third highest manufactured nanoparticle (MNP) produced by volume, with current annual production exceeding 300 tons globally (Hendren et al., 2011). Ag-MNP are used in textiles, plastics, and medical devices principally for their antimicrobial properties (Osório et al., 2012; Prabhu and Poulose, 2012), although they are also used in electronics, such as in conductive inks (Perelaer et al., 2006). Previous studies demonstrate that Ag-MNPs can be released from composite materials and enter wastewater streams, where the majority of Ag-MNP partition to the sludge (Benn and Westerhoff, 2008),(Kaegi et al., 2013). Nearly $75 \%$ of all households in the United States are serviced by wastewater treatment plants (WWTP), with the majority of the sludge generated being land applied as biosolids to agricultural fields (EPA, 1995). Repeated applications of Ag-MNP laden biosolids constitute the primary route by which Ag-MNPs are expected to be introduced to terrestrial ecosystems (Blaser et al., 2008; Hendren et al., 2013; Whitley et al., 2013). Once released to the environment, many metal and metal oxide MNPs have been shown to undergo biogeochemical transformations (Baalousha et al., 2010; Chun-Nam et al., 2007; Henglein, 1998; Liu et al., 2005). Both laboratory incubation, pilot, and full scale WWTP experiments demonstrate that Ag-MNPs are subject to rapid transformation from $\mathrm{Ag}(0)$ to $\mathrm{Ag}_{2} \mathrm{~S}$ (Kaegi et al., 2011; Levard et al., 2012; Lombi et al., 2013; Ma et al., 2014).

Notwithstanding the likely sulfidation of Ag NMPs, the vast majority of ecotoxicological studies involving Ag-MNPs, have focused on the effects of pristine Ag-MNPs and not sulfidized forms. Several studies have previously shown that pristine Ag-MNPs can cause increased mortality, reduced body length, and compromised reproductive performance in the model soil nematode Caenorhabditis elegans (Choi et al., 2014; Ellegaard-Jensen et al., 2012; Kim et al., 2012; Meyer et al., 2010; Roh et al., 2009; Tyne et al., 2013; Yang et al., 2014b). We previously 
demonstrated that sulfidation of Ag-MNPs greatly reduced their adverse effects on C. elegans mortality, growth, and reproduction (Starnes et al., 2015). Utilizing synchrotron-based X-ray fluorescence (XRF) microscopy we demonstrated that the uptake of Ag was lower for $C$. elegans exposed to sulfidized Ag-MNP compared to pristine Ag-MNP. This demonstrated that the observed toxicity from sAg-MNP was not likely due to uptake and accumulation of Ag. Further, we quantified particle dissolution and its contribution to toxicity in that study which was very low for the sAg-MNP treatment (Starnes et al., 2015). It is possible that the toxicity of sAgMNP could be explained by cuticle damage since internal tissue Ag concentrations were so low. It has also demonstrated that sulfidation significantly reduced the toxicity (mortality and growth) of Ag-MNP to C. elegans (Levard et al., 2013; Starnes et al., 2015). Decreases in toxicity of sulfidized Ag-MNPs compared to pristine Ag-MNPs have also been demonstrated for zebrafish (Danio rerio), duckweed (Lemna minuta), killfish (Fundulus heteroclitus), and Escherichia coli (Levard et al., 2013; Reinsch et al., 2012).

Whether the driving force behind Ag-MNP toxicity in ecological receptors is due solely to effects of released $\mathrm{Ag}^{+}$ions to particle specific effects, or a combination of the two is currently debated. For example, Xiu et al. and Yang et al. independently reported that toxicity, in E. coli and C. elegans respectively, was driven by ions released from Ag-MNP (Xiu et al., 2012; Yang et al., 2012), while others have found that the toxicity of Ag-MNP exceed the equivalent metal salt concentrations in nitrifying bacteria cultures (Choi and Hu, 2008; Meyer et al., 2010; Yin et al., 2011). It has also been reported that toxicity can be driven by a combination of ions and intact nanoparticles (Yang, 2014). Our previous work demonstrates that the importance for toxicity of dissolved ion relative to particle specific effects are dependent on the exposure concentration (Starnes et al., 2015). At low exposure concentrations, effects are dominated by 
release of $\mathrm{Ag}^{+}$ions, while at higher exposure concentrations particle specific effects are more prominent (Starnes et al., 2015).

A powerful emerging tool for investigating potential environmental and ecotoxicological impacts of MNP is the model organism C. elegans, an ubiquitous soil dwelling nematode is primarily associated with decaying plant material (Ellegaard-Jensen et al., 2012; Kim et al., 2012; Maupas, 1901; Meyer et al., 2010; Roh et al., 2010; Roh et al., 2009; Tsyusko et al., 2012; Williams and Dusenbery, 1990). The attractiveness of C. elegans to test MNP toxicity is attributable to the fully mapped genome, invariable cell fate map, short generation time, availability of mutants covering much of the genome, low maintenance cost, and amenability to RNA interference methods (Choi and Hu, 2008; Handy et al., 2012; Kim et al., 2012; Leung et al., 2008; Ma et al., 2009; Roh et al., 2010; Roh et al., 2009; Williams and Dusenbery, 1990; Zhang et al., 2011). Genome wide screening of $C$. elegans have been already used to investigate the effects of MNPs (Ag-, Au-, $\mathrm{CeO}_{2-}$, and $\mathrm{TiO}_{2}$ ) (Cui et al., 2006; Menzel et al., 2009; Roh et al., 2010; Roh et al., 2009; Tsyusko et al., 2012; Viñuela et al., 2010). However, to our knowledge, this is the first study to examine transcriptomic responses to aged sulfidized AgMNPs by a model organism. It is anticipated that transcriptomic responses will elucidate mechanisms of sulfidized Ag-MNP toxicity that we previously reported were not explained by the release of $\mathrm{Ag}^{+}$ions (Starnes et al., 2015).

The objective of this study was to compare the transcriptomic responses of C. elegans exposed to pristine and sulfidized Ag-MNP and $\mathrm{AgNO}_{3}$. We hypothesized that that the mode of toxicity is different between pristine and aged MNPs and that the responses of C. elegans to MNPs would differ from those in response to $\mathrm{AgNO}_{3}$ exposure. To confirm the role of select genes in the mechanisms of toxicity, we also employed experiments with mutant strains and 
RNA interference for selected genes that demonstrated opposite responses to one or more treatments.

\section{Materials and Methods}

\section{Silver nanoparticle synthesis and characterization}

Polyvinylpyrrolidone (PVP) coated (pristine) Ag-MNPs were synthesized and then fully sulfidized (completely converted to $\mathrm{Ag}_{2} \mathrm{~S}$ ). Synthesis and sulfidation as well as characterization of the pristine Ag-MNPs and sulfidized Ag-MNPs (sAg-MNPs) are described in our previous work (Starnes et al., 2015). The particle synthesis methods are also described in the supplemental information (SI). Polyvinylpyrrolidone is one of the most common coatings used for dispersal of Ag-MNPs(Wang et al., 2014). As reported previously, the Ag-MNPs and fully sulfidized Ag-MNP had a zeta potentials in the exposure medium of $-6.1 \mathrm{mV}$ and $-28.1 \mathrm{mV}$, respectively, as determined by phase analysis light scattering. The Z-average hydrodynamic diameters for Ag-MNP and sAg-MNP suspended in the exposure medium (described below) as determined by dynamic light scattering was $79.6 \pm 0.5 \mathrm{~nm}$ and $88.5 \pm 0.5 \mathrm{~nm}$, respectively. Complete sulfidation of the Ag-MNPs was verified by powder X-ray diffraction as described in Starnes et al., (2015). Ag concentrations of all stock solutions used to prepare the exposures were determined using inductively coupled plasma mass spectrometry (ICP-MS) after digestion of the particles in aqua regia. We also quantified the dissolution of the of both Ag-MNP and sAg-MNP over the exposure period of $24 \mathrm{~h}$ without presence of bacteria and C. elegans using ultracentrifugation and ICP-MS in our previous work and found dissolution rates of 5.8\% and $0.43 \%$ respectively (Starnes et al, 2015) Unfortunately, dissolution is not readily measured in the presence of biomass. Any Ag ions bound to bacterial cells or nematodes would be removed by ultrafiltration or ultracentrifugation and not accounted for in the dissolution measurement. To 
measure loss of Ag to the exposure container walls, we incubated asset of three replicates of exposure solutions for $24 \mathrm{~h}$ and then removed the solutions and analyzed them. Concentrations were compared to solutions acid digested directly in the tubes without removal.

\section{Nematode exposure and microarrays}

Wild type N2 Bristol strain of C. elegans were obtained from the Caenorhabditis Genetics Center (CGC). Caenorhabditis elegans were age-synchronized using $\mathrm{NaClO} / \mathrm{NaOH}$ solution to isolate eggs. The eggs were placed on K-agar plates with bacterial lawns until needed. All exposures were carried out in moderately hard reconstituted water $\left(4 \mathrm{mg} \mathrm{L}^{-1} \mathrm{KCl}, 60\right.$ $\left.\mathrm{mg} \mathrm{L}^{-1} \mathrm{MgSO}_{4}, 60 \mathrm{mg} \mathrm{L}^{-1} \mathrm{CaSO}_{4}, \mathrm{mg} \mathrm{L}^{-1}, 96 \mathrm{mg} \mathrm{L}^{-1} \mathrm{NaHCO}_{3}\right)(\mathrm{EPA}, 2015)$.

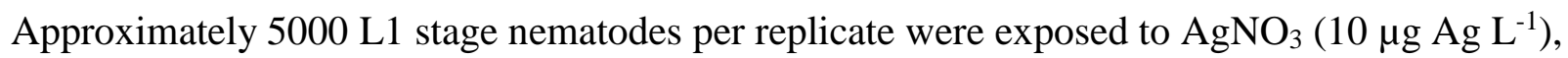
$\operatorname{Ag}-\mathrm{MNP}\left(350 \mu \mathrm{g} \mathrm{Ag} \mathrm{L}^{-1}\right)$, and sAg-MNP (1500 $\left.\mu \mathrm{g} \mathrm{Ag} \mathrm{L}^{-1}\right)$ for 48 hours. The selected concentrations were the $\mathrm{EC}_{30}$ values for reproduction based on our previous work (Starnes et al., 2015). The equitoxic concentrations, corresponding to the $\mathrm{EC}_{30}$ for reproduction for each substance, were chosen so that modes of toxicity could be differentiated where the severity and nature of the effects was similar rather than examining transcriptomic responses at similar Ag concentrations, which would have resulted in a very different nature and severity of effects. The exposures were conducted in the presence of bacterial food, E. coli (OP50 strain), at the rate of $10 \mu \mathrm{L}$ stock solution per $\mathrm{mL}$ of exposure solution $\left(\mathrm{OD}_{600}=1\right.$ for stock solution). To ensure a consistent exposure over the course of 48 hours exposure solutions were replaced after $24 \mathrm{~h}$ with fresh ones and fresh bacterial food was added. Exposures were carried out in $15 \mathrm{~mL}$ polypropylene centrifuge tubes containing $4 \mathrm{~mL}$ of exposure solution. The tubes were arranged horizontally in the incubator and three replicates per treatment were prepared. After exposure the nematodes were twice washed for 30 minutes with bacteria free moderately hard 
reconstituted water to remove most of the bacteria from the nematodes. Bacterial RNA contamination is not a concern since the techniques for measuring mRNA concentrations are sequence specific to C. elegans. RNA was then extracted from each replicate using Trizol with subsequent purification with Qiagen RNAeasy Kit (Qiagen, Chatsworth, CA). Cells were lysed using multiple freeze-thaw cycles $\left(-80\right.$ and $\left.37^{\circ} \mathrm{C}\right)$ as previously described (Tsyusko et al., 2012). All samples were checked for RNA degradation using a Nanodrop ND-2000 spectrophotometer and Agilent 2100 Bioanalyzer to examine the quality and quantity of the RNA samples. All RNA samples had RNA integrity numbers of 9 and above and were sent to the Microarray Core Facility at the University of Kentucky to be processed using Affymetrix C. elegans whole genome microarrays. Total of $1 \mu \mathrm{g}$ of RNA was used to prepare the biotin-labeled cRNA probes, which were hybridized to the microarray chips for 16 , washed in fluidics station, and stained following standard GeneChip expression analysis technical manual. The chips were scanned using Affymetrix GCS 3000 7G scanner. Raw data files were normalized using the robust multiarray average (RMA) algorithm followed by quantile normalization implemented in Partek Genomics Suite 6.4 (Partek, Inc., St. Louis, MO)(Irizarry et al., 2003a). Data were screened for differences of each treatment ( $\mathrm{Ag}-\mathrm{MNP}$, sAg-MNP, and $\mathrm{AgNO}_{3}$ ) from control using one-way ANOVA with contrasts. The false discovery rate (FDR) threshold was set at 0.2 and the fold change was required to be greater than \pm 1.5 , and a P-value $\leq 0.05$. The FDR of 0.2 was selected to balance the protection against false positives while minimizing the rate of false negatives. Using Partek, genes that were significantly different from control in at least one treatment were then analyzed using agglomerative hierarchical cluster analysis (HCA). HCA is a 2-Pass clustering method; the first pass is a K-means clustering and in the second pass the K-means clusters are joined by agglomerative clustering (Partek, 2009). Lists of genes that were 
significantly different than control for each treatment were generated in Partek and exported to Integrated Pathway Analysis (IPA, Ingenuity Systems, www.ingenuity.com) to investigate the possible involvement of relevant pathways. These lists were also uploaded to the Database for Annotation, Visualization and Integrated Discovery v 6.7 (DAVID) utilizing functional clustering tools to identify significant changes in enrichments annotations between treatments(Huang et al., 2008). In DAVID functional annotation tool gene ontology terms for biological process (BP), molecular function $(\mathrm{MF})$, cellular compartment $(\mathrm{CC})$, and Kyoto Encyclopedia of Genes and Genomes (KEGG) Pathway were selected. To avoid redundancy in the same gene sets being represented in multiple functional clusters the DAVID options of “GOTERM_BP_ALL”, “GOTERM_MF_ALL, and “GOTERM_CC_ALL” were selected. All microarray data have been submitted to the National Center for Biotechnology Information (NCBI) (Accession number GSE70509).

qRT-PCR: Validation of Microarray Data.

Quantitative reverse transcription polymerase chain reaction (qRT-PCR) analyses were performed on samples in triplicates (both biological and technical) from independent experiment. Glucose-6 phosphate isomerase I (gpi-1) was selected as the reference gene, which had no significant changes across treatments in either microarray or qRT-PCR analysis (Fig. S1). Four differentially expressed genes with one of the highest expression levels and that had opposite responses to one or two treatments were selected for qRT-PCR confirmation. Among them were collagen (col-158), ground-like ( $\mathrm{grl}-20)$, roller ( $\mathrm{rol}-8)$, and nuclear localized metal responsive (numr-1) genes. $300 \mathrm{ng}$ of RNA were converted to cDNA using a High-Capacity RNA-tocDNA kit ${ }^{\mathrm{TM}}$ (Applied Biosystems) and RNA was cleaned with DNAse I for 15 minutes prior to 
cDNA conversion (Qiagen, Chatsworth, CA). qRT-PCR reactions were carried out in $10 \mu \mathrm{L}$ volumes using TaqMan fast advanced master mix, TaqMan gene expression arrays for each gene (Table S1), and diluted 1:19 cDNA. All gene probes (except for numr-1) spanned introns and StepOne Plus system (Applied Biosystems) was used for all amplifications with a program of 10 min at $95{ }^{\circ} \mathrm{C}$, followed by 40 cycles of $10 \mathrm{~s}$ at $95{ }^{\circ} \mathrm{C}$ and $30 \mathrm{~s}$ at $60{ }^{\circ} \mathrm{C}$. All treatments for each gene were run in triplicates. Negative controls and minus reverse transcription (-RT) negative controls were run for every gene/sample to check for DNA contamination.

Toxicity testing using mutant strains and RNA interference.

Mutant strains for rol-8 and numr-1 were obtained from the CGC. Mortality testing for mutant strains were carried out using age synchronized L3 stage nematodes exposed for 24 hours at $25^{\circ} \mathrm{C}$ in the dark to 3 concentrations of $\mathrm{AgNO}_{3}(6.1,7.5,9.1 \mu \mathrm{g} \mathrm{Ag} \mathrm{L}-1), \operatorname{Ag}-\mathrm{MNP}(52,75,85 \mu \mathrm{g}$ $\left.\operatorname{Ag~L}{ }^{-1}\right)$, and sAg-MNP $\left(525,2000,3500 \mu g \operatorname{Ag~L}^{-1}\right)$. Two sample student t-tests were used to test for significant changes in mortality from N2 wild type at each treatment and concentration.

Testing of selected differentially expressed genes (col-158 and $g r l-20)$ using RNAi knock-down was employed by feeding N2 wild-type nematodes $E$. coli strains that expressed the required dsRNA for 2 generations prior to age synchronization for mortality testing(Williams and Dusenbery, 1988). Escherichia coli strains were obtained from Source Bioscience (http://www.sourcebioscience.com/) and standard RNAi protocols were followed (Fraser et al., 2000). Mortality screens for RNAi experiments were carried out under the same conditions described above. To confirm that RNAi was successful, reduction in expression levels of col-158 and $g r l-20$ were verified using qRT-PCR. 


\section{Results and Discussion}

The purpose of this study was to compare the transcriptomic effects of a pristine Ag-MNP, sulfidized sAg-MNP and $\mathrm{AgNO}_{3}$ at similar effect concentrations ( $\mathrm{EC}_{30}$ for reproduction) on $C$. elegans. Each of the three treatments caused a distinct response with only 20 differentially expressed genes shared among them. However, out of these shared genes, 11 responded in opposite directions with 5 ground-like genes $(\mathrm{grl})$ and 6 collagen genes $(\mathrm{col})$ being upregulated in the sAg-MNP and down-regulated in the $\mathrm{AgNO}_{3}$ and $\mathrm{Ag}-\mathrm{MNP}$ treatments (Fig. S2). These differential responses for the shared genes further confirm that the transcriptomic responses are unique to each treatment. A hierarchical cluster analysis based on 571 differentially expressed genes reveals that replicates cluster within their respective treatments, indicating that replicates within a treatment have gene expression profiles with greater similarity to each other than to replicates from a different treatment (Fig. 1). All treatments are grouped in two major clusters, with $\mathrm{AgNO}_{3}$ forming one cluster and the control and both MNPs the second. Within the second cluster, Ag-MNP showed the greatest dissimilarity to both controls and sAg-MNP. 


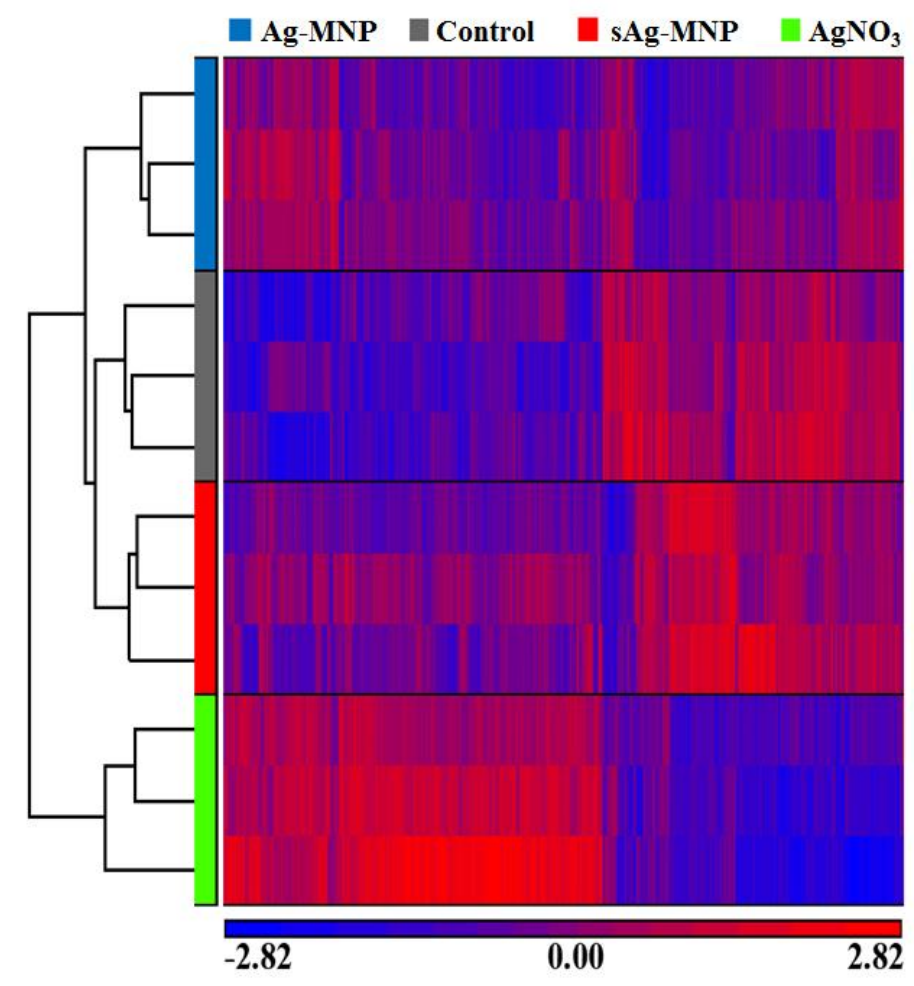

Figure 1. Hierarchical clustering of significantly expressed genes from Caenorhabditis elegans exposed for 48 hours to $\mathrm{Ag}^{+}$, pristine silver manufactured nanoparticles (Ag-MNP), and sulfidized silver manufactured nanoparticles (sAg-MNP) in moderately hard reconstituted water.

Within the set of the 571 differentially expressed genes, only $3.5 \%$ were significantly expressed in all three treatments. Over $85 \%$ of these genes were unique to one of the three treatments. The greatest overlap in significantly expressed genes occurred between $\mathrm{AgNO}_{3}$ and Ag-MNPs and accounted for approximately $10 \%$ of the total differentially expressed genes while the overlap between Ag-MNPs and sAg-MNPs accounted for approximately 5\% of the genes (Fig. 2). These low percentages of shared genes indicate that genomic responses for the sAgMNPs are different from the pristine Ag-MNPs. Our previous work showed more than 10 times as much dissolved Ag was released from the pristine Ag-MNP than from the aged sAg-MNP over the course of the exposure (Starnes et al., 2015). The amount of dissolved Ag released 
from $\mathrm{Ag}$ MNP in the microarray experiment was likely affected by the presence of nematodes and bacteria during exposures. However, our transcriptomic results still indicate that the observed toxicity was not solely caused by the release of Ag ions. Had the toxicity of the AgMNPs been due solely to effects of Ag ions, the replicates of hierarchical clustering would have been randomly distributed and the list of overlapping genes between each MNPs and $\mathrm{AgNO}_{3}$ would have been much larger (Figs. 1 and 2). The percent of Ag lost to the container walls is estimated to be $0 \pm 3.5,33.4 \pm 1.2$ and $30.2 \pm 2.7$ in the $\mathrm{AgNO}_{3}$, Ag-MNP and sAg-MNP treatments, respectively. It is unclear how this affects exposure since the nematodes dwell on the bottom of the container. It also has no implications for the interpretation of the results since the transcriptomic profiles are compared at equitoxic concentrations rather than equal mass concentrations. The toxicity of the sAg-MNP particles could not be due to the release of S since the concentration of $\mathrm{S}$ in the particles was only $1.6 \mu \mathrm{M}$ compared to the $\mathrm{S}$ concentration in the exposure medium of around $850 \mu \mathrm{M}$. Similarly our previous studies showed that the toxicity of the AgMNPs was not due to free PVP polymer in solution (Starnes et al., 2015). Finally, the toxicity is unlikely to be due to an indirect effect on the E. coli OP50 since previous studies have shown that Ag MNP toxicity occurs in E. coli at concentrations approximately 50-100 times greater than our exposure concentrations (Sondi and Salopek-Sondi, 2004). We also did not observe a decrease in cell density at our exposure concentrations. 


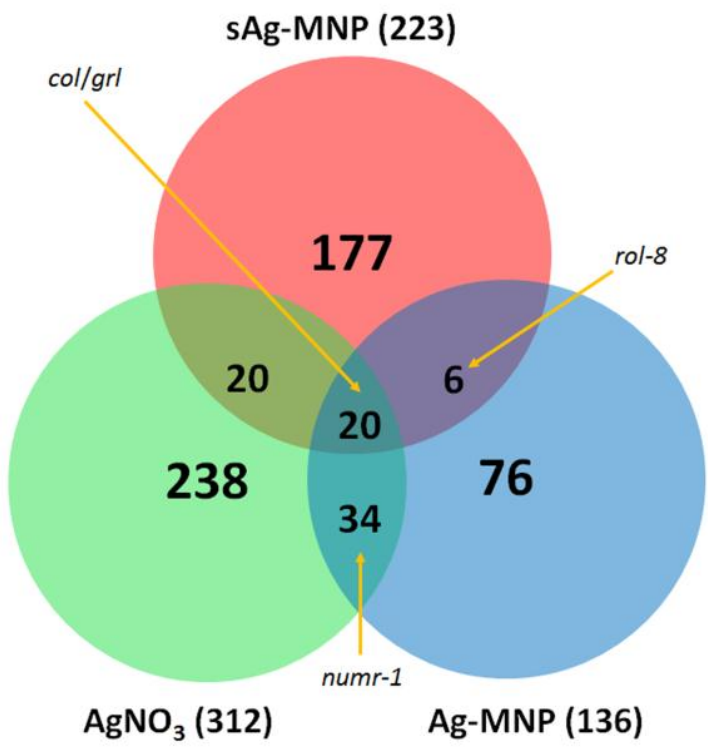

Figure 2. Venn diagram of the significantly up/down regulated genes with a fold change greater than \pm 1.5 , FDR of 0.2 , and $p$-value $\leq 0.05$. Caenorhabditis elegans exposed for 48 hours to $\mathrm{AgNO}_{3}$, pristine Ag manufactured nanoparticles (Ag-MNP), and sulfidized silver manufactured nanoparticles (sAg-MNP) in moderately hard reconstituted water.

There are few toxicogenomic studies examining the effects of MNPs such as Ag-, Au-, and $\mathrm{TiO}_{2}-\mathrm{MNP}$ to $C$. elegans in the literature (Rocheleau et al.; Roh et al., 2009; Tsyusko et al., 2012). These studies have shown that MNPs can alter the gene expression profiles of $C$. elegans in pathways associated with stress response, reproduction, and lysosomal activity. There are limited data to indicate whether the toxicity of soluble NPs, such as Ag and $\mathrm{ZnO}$, is primarily due to the ions or the intact particles. Taken together our data and the data from other $C$. elegans studies suggest that the toxicity of Ag-MNPs is a result of both ionic and intact nanoparticles (Ellegaard-Jensen et al., 2012; Kim et al., 2012; Meyer et al., 2010; Starnes et al., 2015).

qRT-PCR confirmation 
The expressions of four genes selected from the shared and unique gene expression pools were confirmed independently with qRT-PCR (Fig. S3). Among these four genes, there are three related to cuticle function and two of these (col-158, $\mathrm{grl}-20)$ are from the shared pool that were significantly up-regulated only in response to aged sAg-MNP, but down-regulated to AgMNP and $\mathrm{AgNO}_{3}$. The third gene, roller (rol-8), is from the unique genes that responded only to sAg-MNPs and this was also up-regulated. The fourth gene, nuclear metal responsive gene (numr-1), is shared between $\mathrm{Ag}-\mathrm{MNP}$ and $\mathrm{AgNO}_{3}$ and was up-regulated in both exposures, but showed no effect in sAg-MNP exposure. Numr-1 is a nuclear localized metal response gene and therefore should be closely related due to toxicity from metal ion exposure (Tvermoes et al., 2010).

\section{Biological Pathways and Gene Ontology}

No pathways were identified in any treatment using Integrated Pathway Analysis. However, four KEGG pathways in total were identified using DAVID for all treatments ( 1 for each of the MNPs and two for $\mathrm{AgNO}_{3}$ ). These pathways (Table 1) showed no commonality between any of the treatments further confirming uniqueness of the responses. None of these pathways were found by Roh et al., where $C$. elegans was exposed to uncoated pristine Ag-MNP, but this was not unexpected since the current study utilized PVP coated Ag-MNP, a different testing medium, and exposure times that were nearly three times longer than used by Roh (Roh et al., 2009). 
Table 1. List of pathways that were identified by DAVID using lists of significantly altered genes from $\mathrm{N} 2$ wild type nematodes when exposed to $\mathrm{Ag}^{+}$, pristine silver manufactured nanoparticles (AgMNP), and sulfidized silver manufactured nanoparticles (sAg-MNP) at the LC30 for 48 hours.

\begin{tabular}{|c|c|c|c|c|c|}
\hline KEGG ID & Pathway & $\begin{array}{c}\text { Genes in } \\
\text { Pathway }\end{array}$ & $\begin{array}{c}\text { Fold } \\
\text { Enrichment }\end{array}$ & P-Value & Exposure \\
\hline cel00982 & Drug Metabolism & 5 & 1.8 & 0.0026 & $\mathrm{AgNO}_{3}$ \\
\hline cel00680 & Methane Metabolism & 3 & 1.1 & 0.0083 & $\mathrm{AgNO}_{3}$ \\
\hline cel04142 & Lysosome & 5 & 7.5 & 0.0025 & $\mathrm{Ag}^{-M N P}$ \\
\hline cel04020 & Calcium Signaling Pathway & 3 & 1.5 & 0.0057 & sAg-MNP \\
\hline
\end{tabular}

For pristine Ag-MNP, 5 genes were identified in the lysosomal pathway suggesting that lysosomes are involved in processing the particles. Results from previous studies of MNP in both in-vivo as well as in-vitro models have implicated that lysosomes are involved in the detoxification of several types of $\mathrm{MNP}(\mathrm{Au}, \mathrm{Ag}$, and $\mathrm{Fe}$ ), the acidic nature of the lysosome may promote the dissolution of the MNP (Levy et al., 2011; McCarthy et al., 2013; Shukla et al., 2005; Yang et al., 2014a). Yang et al. demonstrated that using lysosomal function mutants greatly enhanced the toxicity of Ag-MNP, though different genes and Ag-MNP were utilized in the study, there is a clear indication that lysosomes are integral to the toxic response in $C$. elegans (Yang, 2014). Three of the genes in the lysosome pathway were hypothetical proteins and two were cysteine protease related genes (cpr-1 and cpr-2) that encode lysosomal proteins. Both $c p r-1$ and $c p r-2$ were significantly down-regulated in Ag-MNP exposures. One of the cysteine protease related genes, $c p r-1$, has been linked to the proper protein degradation within lysosomes while the other, $c p r$-2, has been linked to immune response of C. elegans to Staphylococcus aureus infection (Britton et al., 1998; JebaMercy et al., 2011; Levard et al., 2011). Additionally, $c p r-2$ is a orthologue of the human cathespin b gene (ctsb) which is a lysosomal cysteine protease and has a role in the progression of chronic inflammatory diseases 
such as rheumatoid arthritis and neurodegenerative diseases such as Alzheimer's (Hook et al., 2014; Tong et al., 2014).

In the sAg-MNP exposure, the calcium signaling pathway was identified and the three genes associated with it were all found to be significantly down-regulated such as (egg laying deficient (egl-30), and two uncoordinated (unc-43, unc-68) genes. All three of these genes have been linked to egg laying, additionally $u n c-43$ and $u n c-68$ are also involved in locomotion, cell fate determination, and synaptic regulation (EPA, 2015; Huang et al., 2008; Irizarry et al., 2003b; Williams and Dusenbery, 1988). This finding provide support for our previous results which showed that reproduction was significantly reduced when the nematodes were exposed to sAgMNP (Adachi and Kagawa, 2003; Reiner et al., 1999; Reiner et al., 1995; Starnes et al., 2015; Wang and Wadsworth, 2002). Interestingly, sAg-MNP induced a calcium signaling pathway (cel04020) that was also identified by Tsyusko et al., when exposing C. elegans to Au nanoparticles (Tsyusko et al., 2012). However, the genes associated with this pathway in this study were different from those in the Au-NP study.

Two pathways were identified in the $\mathrm{AgNO}_{3}$ exposure. The first, drug metabolism pathway, contained two significantly down-regulated genes (hypothetical dehydrogenase protein and flavin containing monooxygenase $f m o-2)$ and three genes that were significantly upregulated (glutathione S-transferase gst-10, gst-30, and UDP-glucuronosyl transferase ugt-50). One of the significantly down-regulated genes, fmo-2, has already been shown upregulated in $\mathrm{AgNO}_{3}$ and Ag-MNP toxicity (Eom et al., 2013). However, Eom et al. used a shorter exposure time with a higher dose of $\mathrm{AgNO}_{3}$ than the current study (Eom et al., 2013). The three upregulated genes in the pathway are all phase II xenobiotic detoxification enzymes (Hasegawa and Miwa, 2010; Hasegawa et al., 2010; Nair and Choi, 2011). The second pathway, methane metabolism, had 
three catalase $(c t l)$ genes associated with the pathway that were significantly upregulated. These genes, $c t l-1,2$, and 3 are three catalase genes found in C. elegans, and knockout mutants for $c t l-2$ have been previously shown to cause increases in morality when exposed to Ag-MNP (Ahn et al., 2014). In addition, $c t 1-1$ and 2 are upregulated by daf-16 which is a key part of the stress and aging response associated with the insulin signaling pathway (Murphy, 2013).

For gene ontologies, when investigating the gene list for each treatment a total of 18 Biological Processes (BP), six Molecular Function (MF), and no Cellular Compartment (CC) were identified (Table 2). There was little commonality among the treatments. Ag-MNP gene list returned GO terms related to metabolic processing of enzymes (GO: 0006732) and cofactors (GO: 0018988), while sAg-MNP returned regulation of growth (GO: 0045927), molting cycle (GO: 0018988) and post-embryonic development (GO: 00009791) terms. The tenth GO term for aging identified for Ag-MNPs (GO: 0007568) was shared with $\mathrm{AgNO}_{3}$ and was the only $\mathrm{BP}$ GO term that was shared among the treatments. $\mathrm{AgNO}_{3}$ had nine out of ten $\mathrm{GO}$ terms relating to stress terms such as heat (GO: 0009408), unfolded protein (GO: 0006986), reactive oxygen species (GO: 0000302), and abiotic stimulus (GO: 0009628).

Table 2. List of Biological Process (BP) and Molecular Function (MF) Gene Ontology terms that were identified by DAVID using lists of significantly altered genes from $\mathrm{N} 2$ wild type nematodes when exposed to $\mathrm{AgNO}_{3}$, pristine Ag manufactured nanoparticles (Ag-MNP), and sulfidized silver nanoparticles (sAg$\mathrm{MNP}$ ) at the EC30 for 48 hours.

\begin{tabular}{|l|l|l|l|l|l|}
\hline Go Term BP & \multicolumn{1}{|c|}{ Category } & $\begin{array}{l}\text { Genes in } \\
\text { Category }\end{array}$ & P-Value & \multicolumn{1}{c|}{$\begin{array}{c}\text { Fold } \\
\text { Enrichment }\end{array}$} & Exposure \\
\hline GO:34976 & Response to ER stress & 5 & $8.60 \mathrm{E}-06$ & 4.03 & $\mathrm{AgNO}_{3}$ \\
\hline GO:0033554 & Cellular Response to Stress & 10 & $2.50 \mathrm{E}-05$ & 4.03 & $\mathrm{AgNO}_{3}$ \\
\hline GO:0006986 & Response to unfolded protein & 5 & $2.80 \mathrm{E}-05$ & 4.03 & $\mathrm{AgNO}_{3}$ \\
\hline GO:0009408 & Response to Heat & 5 & $6.90 \mathrm{E}-04$ & 4.03 & $\mathrm{AgNO}_{3}$ \\
\hline GO:0010033 & Response to Organic Substances & 5 & $3.80 \mathrm{E}-03$ & 4.03 & $\mathrm{AgNO}_{3}$ \\
\hline GO:0009628 & Response to abiotic stimulus & 6 & $9.00 \mathrm{E}-03$ & 4.03 & $\mathrm{AgNO}_{3}$ \\
\hline
\end{tabular}




\begin{tabular}{|c|c|c|c|c|c|}
\hline GO:0007568 & Aging & 12 & 8.40E-04 & 3.17 & $\mathrm{AgNO}_{3}$ \\
\hline GO:0042542 & Response to Hydrogen Peroxide & 4 & $1.60 \mathrm{E}-04$ & 1.88 & $\mathrm{AgNO}_{3}$ \\
\hline GO:0000302 & Response to ROS & 4 & $3.40 \mathrm{E}-04$ & 1.88 & $\mathrm{AgNO}_{3}$ \\
\hline GO:0007568 & Aging & 8 & $8.10 \mathrm{E}-04$ & 3.09 & Ag-MNP \\
\hline GO:00006084 & Acetyl-CoA metabolic process & 3 & $9.30 \mathrm{E}-04$ & 1.69 & Ag-MNP \\
\hline GO:0006732 & Coenzyme metabolic process & 4 & $1.80 \mathrm{E}-02$ & 1.69 & $\mathrm{Ag}-\mathrm{MNP}$ \\
\hline GO:0051186 & Cofactor metabolic process & 4 & $5.00 \mathrm{E}-02$ & 1.69 & Ag-MNP \\
\hline GO:0018988 & Molting cycle, protein-based cuticle & 10 & $5.00 \mathrm{E}-04$ & 3.29 & sAg-MNP \\
\hline GO:0045927 & Positive Regulation of growth & 28 & $1.20 \mathrm{E}-02$ & 1.47 & sAg-MNP \\
\hline GO:0006030 & Chitin metabolic process & 3 & $2.80 \mathrm{E}-02$ & 1.38 & sAg-MNP \\
\hline GO:0006022 & aminoglycan metabolic process & 3 & $3.62 \mathrm{E}-02$ & 1.38 & sAg-MNP \\
\hline GO:00009791 & Post-Embryonic Development & 25 & $3.40 \mathrm{E}-02$ & 1.27 & sAg-MNP \\
\hline GO Term MF & Category & $\begin{array}{l}\text { Genes in } \\
\text { Category }\end{array}$ & P-Value & $\begin{array}{l}\text { Fold } \\
\text { Enrichment }\end{array}$ & Exposure \\
\hline G0:0008233 & peptidase activity & 15 & $1.50 \mathrm{E}-02$ & 1.83 & $\mathrm{AgNO}_{3}$ \\
\hline GO:0017171 & Serine hydrolase activity & 6 & $1.10 \mathrm{E}-02$ & 1.73 & $\mathrm{AgNO}_{3}$ \\
\hline G0:0008238 & exopeptidase activity & 4 & $3.60 \mathrm{E}-02$ & 1.73 & $\mathrm{AgNO}_{3}$ \\
\hline GO:0004096 & Catalase Activity & 3 & $3.00 \mathrm{E}-03$ & 1.12 & $\mathrm{AgNO}_{3}$ \\
\hline GO:0008061 & Chitin binding & 3 & $1.50 \mathrm{E}-02$ & 1.4 & sAg-MNP \\
\hline GO:0001871 & Pattern Binding & 3 & $2.30 \mathrm{E}-02$ & 1.4 & sAg-MNP \\
\hline
\end{tabular}

When the MF clustering was run using DAVID only $\mathrm{AgNO}_{3}$ and sAg-MNP had significant clusters indicated and neither lists had any common terms. GO terms of chitin binding (GO: 0008061) and pattern binding (GO: 0001871) were identified for sAg-MNP. The AgNO 3 gene list contained GO terms such as peptidase activity (GO: 0008233), serine hydrolase activity (GO: 0017171), and catalase activity (GO: 0004096).

All of the MF GO for Ag-MNPs are enzymatic terms whereas the MF GO terms for sAg-MNP related to structural cuticle components of the nematode. This is in agreement with our previous study and supports our hypothesis that the cuticle is the primary target for sAg-MNPs (Starnes et al., 2015). In that study we determined the distribution of $\mathrm{Ag}$ in animals exposed to equitoxic concentrations (LC30 over 4hr) of $\mathrm{AgNO}_{3}, \mathrm{Ag}-\mathrm{MNP}$ and sAg-MNP using synchrotron-based X- 
ray fluorescence microscopy. The nematodes exposed to sAg-MNP had non-detectable internal $\mathrm{Ag}$ concentrations. Animals exposed to pristine $\mathrm{Ag}-\mathrm{MNP}$ or $\mathrm{AgNO}_{3}$ had readily detectable internal Ag concentrations with those in the Ag-MNP treatment being than the $\mathrm{AgNO}_{3}$ treatment. We hypothesized that the toxicity of sAg-MNP could be explained by cuticle damage and these gene expression profiles support this hypothesis, since many genes involved in cuticle structure were differentially expressed in the sAg-MNP treatment.

\section{Toxicity using Mutant Strains and RNA interference}

The four genes used for the qRT-PCR confirmation involved in cuticle funciton (rol-8, col-158, $g r l-20$ ) and metal ion response (numr-1) were further used for the functional testing with $C$.

elegans mutant strains or using RNAi. If there is an increase or decrease in toxicity in the mutant or RNAi knockdowns versus wild type nematodes after exposures to one or several treatments that indicates that these genes are possibly involved in toxicity or detoxification mechanisms. When mortality testing was conduted on the rol-8 mutant strain (Fig. 3a) there were signficant increases in toxicity as compared to wild type nematodes for $\mathrm{AgNO}_{3}$ at 7.5 and $9.1 \mu \mathrm{g} \mathrm{Ag} \mathrm{L}{ }^{-1}$, Ag-MNP only at $52 \mu \mathrm{g} \mathrm{L}^{-1}$, and all levels of sAg-MNP. rol-8 is associated with deformations in the cuticlue of the nematode which causes them to move using a lefthand barrel roll motion (Higgins and Hirsh, 1977). Based on the results of the microarray and qRT-PCR experiements, the signficant increase in rol-8 expression was only observed for the Ag-MNP and sAg-MNP. However, it was suprising to see $\mathrm{AgNO}_{3}$ causing an increase in toxicity in rol-8 mutant. This result may on one hand suggest that the response of this gene is due to released ions. However, since both microarray analysis and the independent qRT-PCR experiments did not show upregulation of rol-8, the increased mortality in rol-8 mutants could be due to the mutant strain being more suceptible to any stressor and or toxicant due to decreased integrity of the cuticle. 
In numr-1 mutants, significant increases in mortality as compared to wild type nematodes were found at all treatment levels in both $\mathrm{AgNO}_{3}$ and $\mathrm{Ag}-\mathrm{MNP}$, but no such increase was observed in sAg-MNP at any level (Fig. 3B). Numr-1 has been shown to be responsive to $\mathrm{AgNO}_{3}$ and its response to pristine $\mathrm{Ag}-\mathrm{MNP}$ and $\mathrm{AgNO}_{3}$ is indicative that some of the effects are also due to dissolved ions (Tvermoes et al., 2010). Our previous study showed that the dissolved Ag released from sAg-MNP (0.43\%) over $24 \mathrm{hr}$ is more than 13 times lower than from pristine $\mathrm{Ag}$ MNP (5.8\%) (Starnes et al., 2015), which would explain why we did not observe up-regulation in numr- 1 expression in response to sAg-MNP. This suggests that numr-1 is involved in toxicity mechanism due to released ions from only pristine but not sAg-MNP.

RNAi knockdown was used for two genes, col-158 and grl-20. The col genes are linked to the structure and function of the cuticle of the nematodes, the $\mathrm{grl}$ genes are in the ground-like group which is the hedgehog related superfamily, whose function, though not yet fully understood, has been linked to cuticle construction(Burglin; Levy and Kramer, 1993; Merris et al., 2007). The $g r l-20$ and another collagen gene col-36, which is also up-regulated in response to sAg-MNP, have been previously suggested to co-regulate each other suggesting similar function. The successful knockdown of both genes was confirmed using qRT-PCR (Fig. S4). No signficant changes in the mortality as compared to wild type nematodes in any treatment or level were observed for these genes (Fig. SI 5a and b). The lack of the effect in these genes could be due to the differences in length of expsoure between the mortality experiments and the reproduction experiments. The col-158 and grl-20 could be involved at time points in the growth cycle outside of the 24 hour mortality experiments. Additionally there are at least 130 cuticle $\mathrm{col}$ genes and at least $33 \mathrm{grl}$ genes that could be compensating for the knockdown of these individual genes(Burglin, 2006; Page, 2007). In addition to these two $\mathrm{col}$ and $\mathrm{grl}$ genes, there were 9 more 
col or $g r l$ genes in the shared pool that were also up-regulated only in response to sAg-MNP. It is possible that multiple genes must be knocked down to observe an increase in toxicity.
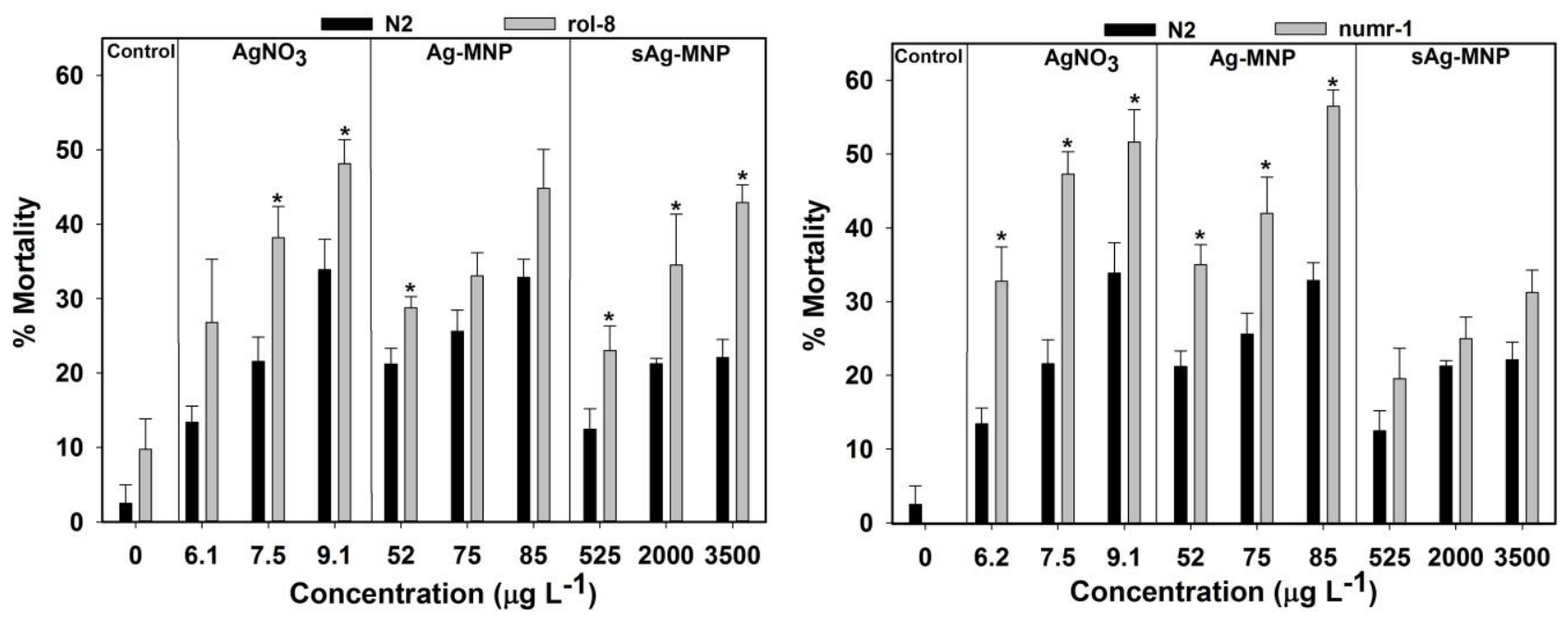

Figure 3. Mortality of L3 Caenorhabditis elegans after 24 hours without feeding exposure to $\mathrm{Ag}^{+}$, pristine silver manufactured nanoparticles (Ag-MNP), and sulfidized silver manufactured nanoparticles (sAg-MNP) in moderately hard reconstituted water. Data are presented as mean percent mortality with error bars indicating standard error of the mean. An asterisk (*) indicates significantly different than N2 at $\alpha=0.05$ within each treatment and concentration.

\section{Conclusions}

This study demonstrates that exposure of $C$. elegans to Ag-MNP and sAg-MNP at EC $30^{-}$ reproduction results in different transcriptomic profiles. Based on these transcriptomic results combined with our previous results relating dissolution, toxicity and Ag bioaccumulation, we conclude that the toxicity of Ag-MNP and sAg-MNP is due to different mechanisms. While the toxicity of pristine Ag-MNP is partly explained by dissolution and release of Ag ions, a proportion of the toxicity is due to particle specific effects. The relative contribution of ionic versus particle specific effects was previously shown to be concentration dependent, however, both mechanisms involve uptake and bioaccumulation of Ag. In contrast, the toxicity of sAg- 
MNP is largely independent of free ion release and Ag bioaccumulation. The results presented here support the hypothesis that cuticle damage is the primary mechanism of toxicity of sAgMNP to C. elegans. While the decreased solubility of sAg-MNP relative to Ag-MNP is correlated with decreased toxicity, release of free ions is not the primary mechanism of reproductive toxicity of fully sulfidized sAg-MNP.

\section{Supporting Information}

Additional text with methods for Ag-MNP synthesis and characterization, four figures, and one table as described in the text. This material is available free of charge via the internet at the Journal of Environmental Science and Technology.

The Authors declare no competing financial interests.

\section{Acknowledgments}

We acknowledge D. Wall and C. Chen for microarray services and R. Ma, B. Collin, D. Arndt, S. Shrestha, and A. Wamucho for laboratory assistance. Caenorhabditis elegans strains were provided by the Caenorhabditis Genetics Center, which is funded by the NIH Office of Research Infrastructure Programs (P40 OD010440). Funding for this research was provided by the United States Environmental Protection Agency (U.S. EPA) Science to Achieve Results Grant RD 834574. JU, GL and OT are supported by the U.S. EPA and National Science Foundation (NSF) under NSF cooperative agreement EF-0830093 and DBI-1266252, Center for Environmental Implications of Nanotechnology (CEINT). SL was partial funded by the Tracy Farmer Institute for Sustainability and the Environment. Any opinions, findings, conclusions, or recommendations expressed in this material are those of the author(s) and do not necessarily 
reflect the views of the EPA or NSF. This work has not been subjected to EPA or NSF review, and no official endorsement should be inferred.

\section{References}

Adachi, R., Kagawa, H., 2003. Genetic analysis of ryanodine receptor function in Caenorhabditis elegans based on unc-68 revertants. Molecular Genetics and Genomics 269, 797-806.

Ahn, J.-M., Eom, H.-J., Yang, X., Meyer, J.N., Choi, J., 2014. Comparative toxicity of silver nanoparticles on oxidative stress and DNA damage in the nematode, Caenorhabditis elegans. Chemosphere 108, 343-352. Baalousha, M., Le Coustumer, P., Jones, I., Lead, J.R., 2010. Characterisation of structural and surface speciation of representative commercially available cerium oxide nanoparticles. Environmental Chemistry 7, 377-385.

Benn, T., Westerhoff, P., 2008. Nanoparticle silver released into water from commercially available sock fabrics. Environ Sci Technol 42, 4133-4139.

Blaser, S.A., Scheringer, M., Macleod, M., Hungerbuhler, K., 2008. Estimation of cumulative aquatic exposure and risk due to silver: contribution of nano-functionalized plastics and textiles. Sci Total Environ 390, 396-409.

Britton, C., McKerrow, J.H., Johnstone, I.L., 1998. Regulation of the Caenorhabditis elegans gut cysteine protease gene cpr-1: requirement for GATA motifs. Journal of molecular biology 283, 15-27. Burglin, T.a.K., P., 2006. Homologs of the Hh signaling network in C. elegans. WormBook, ed. Choi, J., Tsyusko, O., Unrine, J., Chatterjee, N., Ahn, J.-M., Yang, X., Thornton, L., Ryde, I., Starnes, D., Meyer, J., 2014. A micro-sized model for the in vivo studies of nanoparticle toxicity: What has Caenorhabditis elegans taught us? Envir. Chem. 11, 227-246.

Choi, O., Hu, Z., 2008. Size dependent and reactive oxygen species related nanosilver toxicity to nitrifying bacteria. Environ Sci Technol 42, 4583-4588.

Chun-Nam, L., Chi-Ming, H., Rong, C., Qing-Yu, H., Wing-Yiu, Y., Hongzhe, S., Paul, T., Jen-Fu, C., ChiMing, C., 2007. Silver nanoparticles: partial oxidation and antibacterial activities. Journal of Biological Inorganic Chemistry 12, 527-534.

Cui, Y., McBride, S.J., Boyd, W.A., Alper, S., Freedman, J.H., 2006. Toxicogenomic analysis of Caenorhabditis elegans reveals novel genes and pathways involved in the resistance to cadmium toxicity. Genome Biology 8.

Ellegaard-Jensen, L., Jensen, K.A., Johansen, A., 2012. Nano-silver induces dose-response effects on the nematode Caenorhabditis elegans. Ecotoxicol Environ Saf 80, 216-223.

Eom, H.-J., Ahn, J.-M., Kim, Y., Choi, J., 2013. Hypoxia inducible factor-1 (HIF-1)-flavin containing monooxygenase-2 (FMO-2) signaling acts in silver nanoparticles and silver ion toxicity in the nematode, Caenorhabditis elegans. Toxicology and Applied Pharmacology 270, 106-113.

EPA, 1995. A Guide to the Biosolids Risk Assessments for the EPA., Washington, D.C.

EPA, 2015. Clean Water Act analytical methods for measuring the Acute toxicity of effluents and receiving waters to freshwater and marine organisms, Washington, D.C.

Fraser, A.G., Kamath, R.S., Zipperlen, P., Martinez-Campos, M., Sohrmann, M., Ahringer, J., 2000.

Functional genomic analysis of $C$. elegans chromosome I by systematic RNA interference. Nature 408, 325-330.

Handy, R.D., Cornelis, G., Fernandes, T., Tsyusko, O., Decho, A., Sabo-Attwood, T., Metcalfe, C., Steevens, J.A., Klaine, S.J., Koelmans, A.A., Horne, N., 2012. Ecotoxicity test methods for engineered 
nanomaterials: practical experiences and recommendations from the bench. Environ Toxicol Chem 31, 15-31.

Hasegawa, K., Miwa, J., 2010. Genetic and cellular characterization of Caenorhabditis elegans mutants abnormal in the regulation of many phase II enzymes. PLoS ONE 5, e11194.

Hasegawa, K., Miwa, S., Tsutsumiuchi, K., Miwa, J., 2010. Allyl isothiocyanate that induces GST and UGT expression confers oxidative stress resistance on $C$. elegans, as demonstrated by nematode biosensor. PLoS ONE 5, e9267.

Hendren, C.O., Badireddy, A.R., Casman, E., Wiesner, M.R., 2013. Modeling nanomaterial fate in wastewater treatment: Monte Carlo simulation of silver nanoparticles (nano-Ag). Sci Total Environ 449, 418-425.

Hendren, C.O., Mesnard, X., Droge, J., Wiesner, M.R., 2011. Estimating production data for five engineered nanomaterials as a basis for exposure assessment. Environ Sci Technol 45, 2562-2569.

Henglein, A., 1998. Colloidal Silver Nanoparticles: Photochemical Preparation and Interaction with O2, $\mathrm{CCl} 4$, and Some Metal Ions. Chemistry of Materials 10, 444-450.

Higgins, B., Hirsh, D., 1977. Roller mutants of the nematode Caenorhabditis elegans. Molecular and General Genetics MGG 150, 63-72.

Hook, G., Yu, J., Toneff, T., Kindy, M., Hook, V., 2014. Brain Pyroglutamate Amyloid-beta is Produced by Cathepsin B and is Reduced by the Cysteine Protease Inhibitor E64d, Representing a Potential

Alzheimer's Disease Therapeutic. Journal of Alzheimers Disease 41, 129-149.

Huang, D.W.a.W., Sherman, B.T., Lempicki, R.A., 2008. Systematic and integrative analysis of large gene lists using DAVID bioinformatics resources. Nature protocols 4, 44-57.

Irizarry, R.A., Hobbs, B., Collin, F., Beazer-Barclay, Y.D., Antonellis, K.J., Scherf, U., Speed, T.P., 2003a. Exploration, normalization, and summaries of high density oligonucleotide array probe level data.

Biostatistics (Oxford, England) 4, 249-264.

Irizarry, R.A., Hobbs, B., Collin, F., Beazer-Barclay, Y.D., Antonellis, K.J., Scherf, U., Speed, T.P., $2003 b$. Exploration, normalization, and summaries of high density oligonucleotide array probe level data. Biostatistics 4, 249-264.

JebaMercy, G., Pandian, S., Balamurugan, K., 2011. Changes in Caenorhabditis elegans life span and selective innate immune genes during Staphylococcus aureus infection. Folia Microbiologica 56, 373380.

Kaegi, R., Voegelin, A., Ort, C., Sinnet, B., Thalmann, B., Krismer, J., Hagendorfer, H., Elumelu, M., Mueller, E., 2013. Fate and transformation of silver nanoparticles in urban wastewater systems. Water Res 47, 3866-3877.

Kaegi, R., Voegelin, A., Sinnet, B., Zuleeg, S., Hagendorfer, H., Burkhardt, M., Siegrist, H., 2011. Behavior of metallic silver nanoparticles in a pilot wastewater treatment plant. Environ Sci Technol 45, 3902-

3908.

Kim, S.W., Nam, S.H., An, Y.J., 2012. Interaction of silver nanoparticles with biological surfaces of Caenorhabditis elegans. Ecotoxicol Environ Saf 77, 64-70.

Leung, M.C., Williams, P.L., Benedetto, A., Au, C., Helmcke, K.J., Aschner, M., Meyer, J.N., 2008.

Caenorhabditis elegans: an emerging model in biomedical and environmental toxicology. Toxicol Sci 106, 5-28.

Levard, C., Hotze, E.M., Colman, B.P., Dale, A.L., Truong, L., Yang, X.Y., Bone, A.J., Brown, G.E., Jr., Tanguay, R.L., Di Giulio, R.T., Bernhardt, E.S., Meyer, J.N., Wiesner, M.R., Lowry, G.V., 2013. Sulfidation of silver nanoparticles: natural antidote to their toxicity. Environ Sci Technol 47, 13440-13448. Levard, C., Hotze, E.M., Lowry, G.V., Brown, G.E., Jr., 2012. Environmental transformations of silver nanoparticles: impact on stability and toxicity. Environ Sci Technol 46, 6900-6914. 
Levard, C., Reinsch, B.C., Michel, F.M., Oumahi, C., Lowry, G.V., Brown, G.E., 2011. Sulfidation processes of PVP-coated silver nanoparticles in aqueous solution: impact on dissolution rate. Environ Sci Technol 45, 5260-5266.

Levy, A.D., Kramer, J.M., 1993. Identification, sequence and expression patterns of the Caenorhabditis elegans col-36 and col-40 collagen-encoding genes. Gene 137, 281-285.

Levy, M., Luciani, N., Alloyeau, D., Elgrabli, D., Deveaux, V., Pechoux, C., Chat, S., Wang, G., Vats, N., Gendron, F., Factor, C., Lotersztajn, S., Luciani, A., Wilhelm, C., Gazeau, F., 2011. Long term in vivo biotransformation of iron oxide nanoparticles. Biomaterials 32, 3988-3999.

Liu, Y., Majetich, S.A., Tilton, R.D., Sholl, D.S., Lowry, G.V., 2005. TCE Dechlorination Rates, Pathways, and Efficiency of Nanoscale Iron Particles with Different Properties. Environmental Science \& Technology 39, 1338-1345.

Lombi, E., Donner, E., Taheri, S., Tavakkoli, E., Jamting, A.K., McClure, S., Naidu, R., Miller, B.W., Scheckel, K.G., Vasilev, K., 2013. Transformation of four silver/silver chloride nanoparticles during anaerobic treatment of wastewater and post-processing of sewage sludge. Environ Pollut 176, 193-197. Ma, H., Bertsch, P.M., Glenn, T.C., Kabengi, N.J., Williams, P.L., 2009. Toxicity of manufactured zinc oxide nanoparticles in the nematode Caenorhabditis elegans. Environ Toxicol Chem 28, 1324-1330.

Ma, R., Levard, C., Judy, J.D., Unrine, J.M., Durenkamp, M., Martin, B., Jefferson, B., Lowry, G.V., 2014. Fate of zinc oxide and silver nanoparticles in a pilot wastewater treatment plant and in processed biosolids. Environ Sci Technol 48, 104-112.

Maupas, E., 1901. Modes et formes de reproduction des nematodes. Archives de Zoologie expérimentale et générale 8, 463-624.

McCarthy, M.P., Carroll, D.L., Ringwood, A.H., 2013. Tissue specific responses of oysters, Crassostrea virginica, to silver nanoparticles. Aquatic Toxicology 138-139, 123-128.

Menzel, R., Swain, S.C., Hoess, S., Claus, E., Menzel, S., Steinberg, C.E., Reifferscheid, G., Sturzenbaum, S.R., 2009. Gene expression profiling to characterize sediment toxicity--a pilot study using Caenorhabditis elegans whole genome microarrays. BMC Genomics 10, 160.

Merris, M., Wang, T., Soteropoulos, P., Lenard, J., 2007. Differential gene expression of Caenorhabditis elegans grown on unmethylated sterols or $4 \alpha$-methylsterols. Journal of Lipid Research 48, 1159-1166.

Meyer, J.N., Lord, C.A., Yang, X.Y., Turner, E.A., Badireddy, A.R., Marinakos, S.M., Chilkoti, A., Wiesner, M.R., Auffan, M., 2010. Intracellular uptake and associated toxicity of silver nanoparticles in Caenorhabditis elegans. Aquat Toxicol 100, 140-150.

Murphy, C.a.H., P., 2013. Insulin/insulin-like growth factor signaling in C. elegans. WormBook. Nair, P.M.G., Choi, J., 2011. Identification, characterization and expression profiles of Chironomus riparius glutathione S-transferase (GST) genes in response to cadmium and silver nanoparticles exposure. Aquatic Toxicology 101, 550-560.

Osório, I., Igreja, R., Franco, R., Cortez, J., 2012. Incorporation of silver nanoparticles on textile materials by an aqueous procedure. Materials Letters 75, 200-203.

Page, A., and Johnstone, I., 2007. The cuticle. WormBook, ed.

Partek, 2009. Partek Genomics Suite 6.4. Partek Inc., St. Louis, MO.

Perelaer, J., de Gans, B.J., Schubert, U.S., 2006. Ink-jet Printing and Microwave Sintering of Conductive Silver Tracks. Advanced Materials 18, 2101-2104.

Prabhu, S., Poulose, E., 2012. Silver nanoparticles: mechanism of antimicrobial action, synthesis, medical applications, and toxicity effects. International Nano Letters 2, 1-10.

Reiner, D.J., Newton, E.M., Tian, H., Thomas, J.H., 1999. Diverse behavioural defects caused by mutations in Caenorhabditis elegans unc-43 CaM Kinase II. Nature 402, 199-203.

Reiner, D.J., Weinshenker, D., Thomas, J.H., 1995. Analysis of dominant mutations affecting muscle excitation in Caenorhabditis elegans. Genetics 141, 961-976. 
Reinsch, B.C., Levard, C., Li, Z., Ma, R., Wise, A., Gregory, K.B., Brown, G.E., Lowry, G.V., 2012. Sulfidation of silver nanoparticles decreases Escherichia coli growth inhibition. ENVIRONMENTAL SCIENCE \& TECHNOLOGY 46, 6992-7000.

Rocheleau, S., Arbour, M., Elias, M., Sunahara, G.I., Masson, L., Toxicogenomic effects of nano- and bulkTiO2 particles in the soil nematode Caenorhabditis elegans. Nanotoxicology 0, 1-11.

Roh, J.Y., Park, Y.K., Park, K., Choi, J., 2010. Ecotoxicological investigation of $\mathrm{CeO}(2)$ and TiO(2)

nanoparticles on the soil nematode Caenorhabditis elegans using gene expression, growth, fertility, and survival as endpoints. Environ Toxicol Pharmacol 29, 167-172.

Roh, J.Y., Sim, S.J., Yi, J., Park, K., Chung, K.H., Ryu, D.Y., Choi, J., 2009. Ecotoxicity of silver nanoparticles on the soil nematode Caenorhabditis elegans using functional ecotoxicogenomics. Environ Sci Technol 43, 3933-3940.

Shukla, R., Bansal, V., Chaudhary, M., Basu, A., 2005. Biocompatibility of gold nanoparticles and their endocytotic fate inside the cellular compartment: a microscopic overview. Langmuir.

Sondi, I., Salopek-Sondi, B., 2004. Silver nanoparticles as antimicrobial agent: a case study on E. coli as a model for Gram-negative bacteria. Journal of Colloid and Interface Science.

Starnes, D.L., Unrine, J.M., Starnes, C.P., Collin, B.E., Oostveen, E.K., Ma, R., Lowry, G.V., Bertsch, P.M., Tsyusko, O.V., 2015. Impact of sulfidation on the bioavailability and toxicity of silver nanoparticles to Caenorhabditis elegans. Environmental Pollution 196, 239-246.

Tong, B., Wan, B., Wei, Z., Wang, T., Zhao, P., Dou, Y., Lv, Z., Xia, Y., Dai, Y., 2014. Role of cathepsin B in regulating migration and invasion of fibroblast-like synoviocytes into inflamed tissue from patients with rheumatoid arthritis. Clinical \& Experimental Immunology 177, 586-597.

Tsyusko, O.V., Unrine, J.M., Spurgeon, D., Blalock, E., Starnes, D., Tseng, M., Joice, G., Bertsch, P.M., 2012. Toxicogenomic responses of the model organism Caenorhabditis elegans to gold nanoparticles. Environ Sci Technol 46, 4115-4124.

Tvermoes, B.E., Boyd, W.A., Freedman, J.H., 2010. Molecular characterization of numr-1 and numr-2: genes that increase both resistance to metal-induced stress and lifespan in Caenorhabditis elegans.

Journal of Cell Science 123, 2124-2134.

Tyne, W., Lofts, S., Spurgeon, D.J., Jurkschat, K., Svendsen, C., 2013. A new medium for Caenorhabditis elegans toxicology and nanotoxicology studies designed to better reflect natural soil solution conditions. Environ Toxicol Chem 32, 1711-1717.

Viñuela, A., Snoek, L.B., Riksen, J.A.G., Kammenga, J.E., 2010. Genome-wide gene expression enalysis in response to organophosphorus pesticide chlorpyrifos and diazinon in C. elegans. PLoS ONE 5, e12145. Wang, H., Burgess, R.M., Cantwell, M.G., 2014. Stability and aggregation of silver and titanium dioxide nanoparticles in seawater: Role of salinity and dissolved organic carbon. Environmental ....

Wang, Q., Wadsworth, W.G., 2002. The $C$ domain of netrin UNC-6 silences calcium/calmodulindependent protein kinase and diacylglycerol-dependent axon branching in Caenorhabditis elegans. The Journal of Neuroscience 22, 2274-2282.

Whitley, A.R., Levard, C., Oostveen, E., Bertsch, P.M., Matocha, C.J., von der Kammer, F., Unrine, J.M., 2013. Behavior of Ag nanoparticles in soil: effects of particle surface coating, aging and sewage sludge amendment. Environ Pollut 182, 141-149.

Williams, P.L., Dusenbery, D.B., 1988. Using the nematode Caenorhabditis elegans to predict mammalian acute lethality to metallic salts. Toxicol. Ind. Health 4, 469-478.

Williams, P.L., Dusenbery, D.B., 1990. Aquatic toxicity testing using the nematode, Caenorhabditis elegans. Environ Toxicol Chem 9, 1285-1290.

Xiu, Z.M., Zhang, Q.B., Puppala, H.L., Colvin, V.L., Alvarez, P.J., 2012. Negligible particle-specific antibacterial activity of silver nanoparticles. Nano Lett 12, 4271-4275.

Yang, X., 2014. Mechanisms of silver nanoparticle toxicity in laboratory suspensions and complex environmental media in Caenorhabditis elegans, Environment. Duke, Duke Univeristy, p. 194. 
Yang, X., Gondikas, A.P., Marinakos, S.M., Auffan, M., Liu, J., Hsu-Kim, H., Meyer, J.N., 2012. Mechanism of silver nanoparticle toxicity is dependent on dissolved silver and surface coating in Caenorhabditis elegans. Environ Sci Technol 46, 1119-1127.

Yang, X., Jiang, C., Hsu-Kim, H., Badireddy, A., Dykstra, M., Wiesner, M., Hinton, D.E., Meyer, J.N., 2014a. Silver nanoparticle behavior, uptake, and toxicity in Caenorhabditis elegans: effects of natural organic matter. Environmental science \& technology 48, 3486-3495.

Yang, X., Jiang, C., Hsu-Kim, H., Badireddy, A.R., Dykstra, M., Wiesner, M., Hinton, D.E., Meyer, J.N., 2014b. Silver nanoparticle behavior, uptake, and toxicity in Caenorhabditis elegans: effects of natural organic matter. Environ Sci Technol 48, 3486-3495.

Yin, L., Cheng, Y., Espinasse, B., Colman, B.P., Auffan, M., Wiesner, M., Rose, J., Liu, J., Bernhardt, E.S., 2011. More than the ions: the effects of silver nanoparticles on Lolium multiflorum. Environ Sci Technol 45, 2360-2367.

Zhang, H., He, X., Zhang, Z., Zhang, P., Li, Y., Ma, Y., Kuang, Y., Zhao, Y., Chai, Z., 2011. Nano-CeO2 exhibits adverse effects at environmental relevant concentrations. Environ Sci Technol 45, 3725-3730. 